\title{
DIGITAL OCCUPATIONAL HEALTH SYSTEMS: WHAT DO EMPLOYEES THINK ABOUT IT?
}

\author{
Maedeh Yassaee ${ }^{1}$,Tobias Mettler ${ }^{2^{\bowtie}}$ \\ ${ }^{1}$ University of St. Gallen, Institute of Information Management, Unterer Graben 21, CH-9000 \\ St. Gallen, Switzerland; E-mail: maedeh.yassaee@unisg.ch \\ 2 University of Lausanne, Swiss Graduate School of Public Administration, Rue de la Mouline 28, CH-1022 \\ Chavannes-près-Renens, Switzerland; E-mail: tobias.mettler@unil.ch; tel: +41216926950
}

Citation: Yassaee M, Mettler T. Digital occupational health systems: What do employees think about it? Information Systems Frontiers; https://doi.org/10.1007/s10796-017-9795-6

\begin{abstract}
A high rate of work-related accidents or diseases around the world not only threatens the health and wellbeing of employees, but also causes a considerable annual economic burden for organizations. One promising use of information technology would therefore be the management and prevention of occupational accidents and employee absenteeism. Although some companies are starting to introduce digital occupational health initiatives, there is scarce evidence about the inhibiting factors which may discourage the wide adoption of such systems in the workforce. This paper presents qualitative and quantitative data of an exploratory study, which delves into the perceptions of employees towards the use of digital occupational health systems. Our results show that employees are usually aware of the enhanced possibilities for managing and improving their health and wellbeing through such corporate initiatives. However, privacy concerns and the additional mental pressure caused by such systems, significantly diminishes an employee's willingness to adopt them.
\end{abstract}

\section{Keywords}

Digital occupational health; mixed methods; sensor-based systems; technology adoption 


\section{Introduction}

Most of the world's population spend one-third of their adult life at work (World Health Organization 1995). Work may have both positive and negative effects on the health of employees (World Health Organization 1995). Research has shown a high rate of work-related accidents and transmission of diseases (Wilson and Sharples 2015). In addition to that there is also an increasing level of work-related stress and psychosocial risks faced by many of today's workers (Nieuwenhuijsen et al. 2010). While organizations are legally responsible for protecting the safety and health of their employees (Lekaa et al. 2010), the current state of work environments in industrialized countries indicates that the organizations are not particularly successful in this regard. Following the widespread use of digitized personal health monitoring systems in private (frequently referred to as quantified-self) and clinical context (known as physiolytics), organizations have started to provide their employees with wearable devices as part of their occupational safety and health programs (Fingas 2015; Olson 2014; Vyas et al. 2015). In this study, the term digital occupational health systems (DOHS) is used to refer to digitized health monitoring systems which are designed for the use in organizational settings for promoting health and wellbeing among the workforce. The technologies required to enable DOHS goals consist of three main categories: hardware (e.g. sensors, actuators) for collecting physiological, movement, or environmental data; hardware and software for relaying data to a remote center; and data analysis techniques for extracting clinically relevant and business-critical information (Atallah et al. 2009; S. Patel et al. 2012).

Although the adoption of digitized personal health monitoring systems has been studied in both private and clinical contexts (Sun and Qu 2015), corporate adoption of such systems has distinct, yet hardly investigated characteristics. Sensitive and highly personal health-related information collected in a non-health context impacts employees' privacy (Pozzi et al. 2014). On the other hand, work and private life integration through the introduction of DOHS may cause tensions, in particular between work and leisure activities or different roles in business and private life. Since organizations cannot force employees to adopt the system (due to legal reasons related to the protection of personal information), employees will either completely reject the technology or selectively adopt particular features in cases of tensions (Leonardi 2011). Therefore, this research seeks to understand the employees' expectations and factors influencing their adoption behavior of DOHS. In this effort, the notion of "affordance" is used as a theoretical lens, which emphasizes the specific functionality of the technology and considers the user's individual situation when analyzing their adoption behavior (Majchrzak and Markus 2012; Grgecic et al. 2015). The concept of affordances can bridge the gap between theories that emphasize only psychological or social behaviors and concepts that ignore the role of human intention and behavior (Piccoli and Pigni 2013; Vitari and Pigni 2014). Specifically, this work investigates the following two research questions: What affordances influence employees' use intention of DOHS? What factors affect employees' abilities to perceive these affordances?

This study aims to contribute to existing IT adoption research by acquiring an affordance approach to study the users' attitude towards different functionalities of DOHS. Our work also contributes to the research and practice of DOHS adoption in organizations. Our contribution to research is an attempt to bridge the gap between designer intentions (functions) and the employees' use intentions as the primary end user of this system in existing. Practitioners who wish to design or use DOHS in an organizational setting might use the findings of this research to increase participants' use of DOHS. 
The paper is structured in the following way: we first explain why using an affordance perspective to examine user attitude and intention of use for technology innovation is especially relevant. We then detail our data collection and analysis procedures and explain our findings.

\section{Theoretical foundations}

\subsection{User adoption and perceived affordance}

Individuals as active adopters of innovations utilize different innovations and then spread their use (at different rates) to other individuals. While some innovations are quickly and widely adopted, some are never accepted or subsequently abandoned. It has been argued that adoption is a process rather than an event, with different concerns being dominant at different stages. These stages include: pre-adoption, early use, and established use (Greenhalgh et al. 2004). Information technology (IT) is a social product; the development of the technology evolves through the social groups such as designers, implementers, management and users (Balci et al. 2014; Grgecic et al. 2015). Thus, the separation of these groups place serious limitations on understanding the relationship between the social dynamics of technology development and the social dynamics of its use (Leonardi and Barley 2010). Throughout the pre-adoption stage, communication of unambiguous relative advantages as a sine qua non for use will provide a foundation for successful adoption if it occurs within the design and implementation phase (Moore and Benbasat 1991). In this phase, innovations should undergo a period of negotiation among potential adopters, during which time the relative advantages are discussed, contested, and reframed (Moore and Benbasat 1991). However, IT adoption models and theories mainly start their investigation of acceptance and adoption at the time of implementation or after (early and established use stages) (Faraj and Azad 2012) and presume that users use the technology as initially intended by the management and the system designers.

In IT adoption models and theories, the concept of perceived value is often understood "as a person's evaluation of the entity in question" which predicts the use intention of the adopter (Ajzen and Fishbein 1977). Perceived value is considered to include hedonic and utilitarian benefits. Following van der Heijden (2004), the term "hedonic" is used in the literature to denote the components of a system that "aim to provide self-fulfilling value to the user," whereas the "utilitarian" components of a system refer to features that “aim to provide instrumental value to the user.” (D. J. Wu et al. 2013). The most well-known examples of perceived utilitarian value are perceived usefulness and ease of use (Davis 1986). However, these concepts often treat technology as black box (e.g. investigate how users perceive the technology as a whole) and therefore lack detailed insights (on feature level). For instance, perceived usefulness has been defined as "the extent to which a person believes that using a particular system as a whole [will] enhance their work performance” (Davis 1989). IT adoption can occur at a feature or a functional level (Al-Natour and Benbasat 2009; Grgecic et al. 2015; Leonardi and

Barley 2010). Users tend to reject or use features for other reasons than designers initially intended (e.g., some features may be unused, misunderstood, or remain undiscovered by users) (Leonardi 2011).

Contrary to the concept of perceived value in IT adoption models and theories, the concept of perceived affordance helps to differentiate between intentions of IT designers (embodied as functions) and the impact of those functions on user's attitude that shapes users' actions (Leonardi 2013; Markus and Silver 2008). 
Ecological psychologist James Gibson (1979) centered his affordance theory on the possibility of actions that an object in an environment offers to an organism. Since then, the concept of affordance has evolved from describing animalenvironmental systems to describe sociotechnical systems (Fayarda and Weeks 2014) in diverse socio-material contexts such as human computer interaction (HCI) (Norman 1988), engineering design (Maier et al. 2009) and information systems (Leonardi 2011; Markus and Silver 2008). However, the concept of affordance has been used in different ways, with different objectives in each of these contexts.

Affordances are "conditions" that enable "interactions" among users and IT artefacts (Fayarda and Weeks 2014). These conditions include properties related to the social actor (e.g., individual and organizational expectations, motivations, needs, and knowledge) and the technical artefact (its functions or features) (Pozzi et al. 2014). Therefore, affordances are "functional [enabling and constraining] and relational [e.g., different for one individual than for another] aspects which frame, while not determining, the possibilities for agentic action in relation to an object" (Hutchby 2001). Norman (1988) introduced the concept of perceived affordances to distinguish between the functional and relational aspects of affordance in his book The Psychology of Everyday Things. He appropriated affordance as a "designed-in" property of an artifact and distinguished between affordance as the set of action possibilities designed in the object and the perceived affordance as the actions which user perceives to be possible based on his or her instincts and mental model, expectation, knowledge, and the environment in which the interaction takes place (Norman 1999). Therefore, the subject-object interaction is only possible when the perceived affordance is aligned with the affordance of an object. In this study, it is our objective to understand the functional (designed-in property) and relational (user's perception) aspects of DOHS affordances.

\section{Research approach}

The initial part of this section describes the context within which the study takes place. We then describe the research design, outline our reasoning for adopting a mixed method approach, and describe the two phases of the research process and the methodological choices made in each phase.

\subsection{Study context}

The results presented in this work are based on the Active@work project, an endeavor funded by the European Commission and Swiss State Secretariat for Education, Research, and Innovation. The main goal of this project is to facilitate senior employees efficiently performing their jobs without risking their health. Active@work uses a modular approach (cognitive, skill development, and collaborative) to manage the negative impacts of aging - both physiological and psychological - on employees' performance and productivity. The focus of this study is on the cognitive module. However, in the following, the other modules are also briefly introduced. Figure 1 illustrates an overview of the general architecture of the system and the scope of this study. 


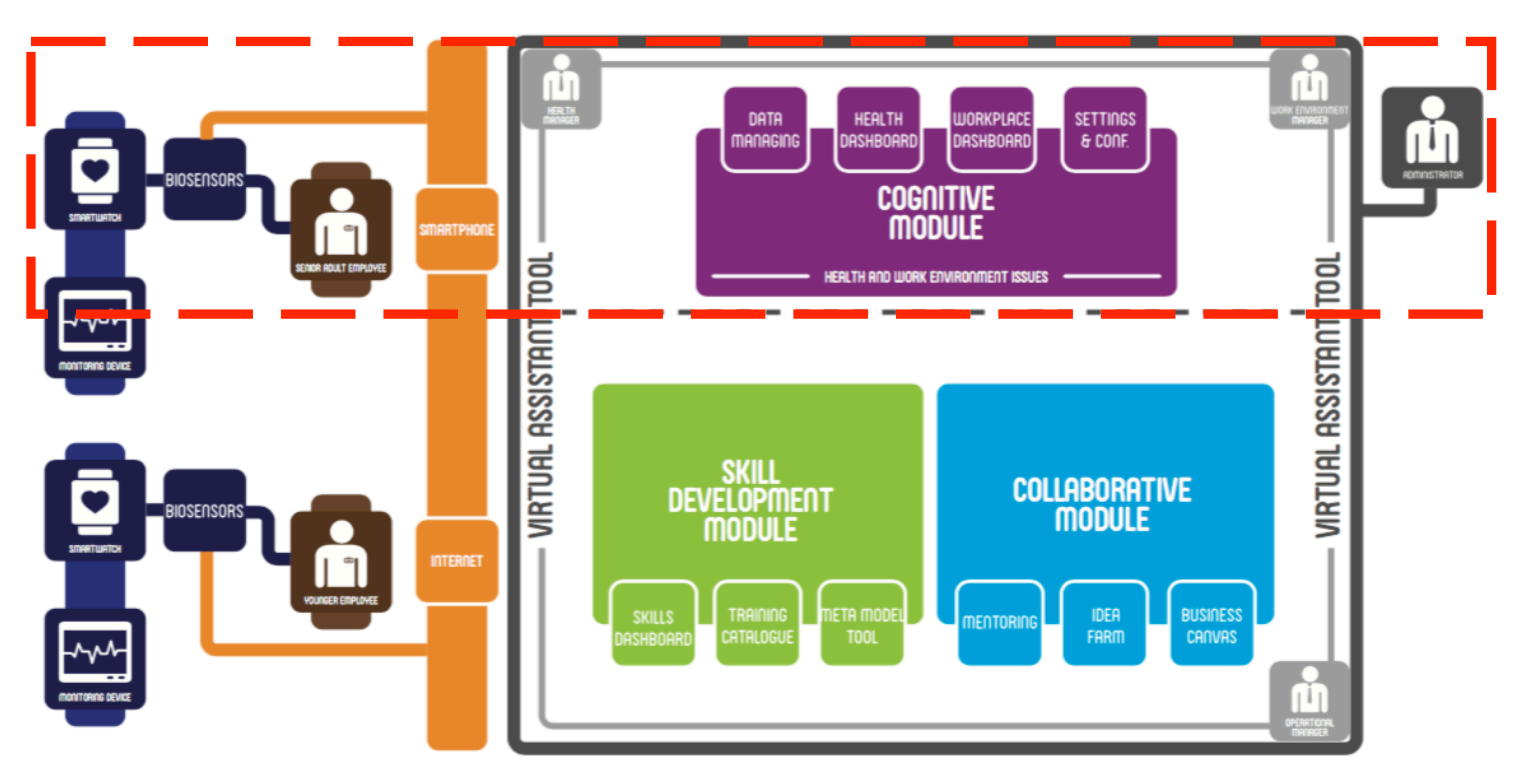

Fig. 1 Architecture of Active@work artifact and scope of this study

The skills development module helps employees to improve their expertise and informs them about soft and hard skills they should acquire to keep up with today's work requirements. The collaborative module's main objective is to share knowledge, ideas, and best practices with members of the Active@work community, specifically between senior and junior employees. This module promotes active participation and interaction between employees by sharing experiences and mentoring the implementation of new business ideas.

Within the cognitive module, which is the focus of this study, the goal is to improve the employees' health by monitoring both their body conditions and work environment. The design and implementation of this module consists of a sensorbased solution that allows senior workers to monitor their health status during work, predict work distress/fatigue, and alert them (and provide warnings) so that they can take corrective action. More specifically, it is possible (a) to monitor the environmental conditions in the workplace with the help of environmental sensors (e.g., air quality, temperature, noise, etc.), (b) wirelessly report these data to a central server for processing, (c) provide operational intelligence with a proactive model and predictive algorithms for recognizing behavioral trends and early detection of personal health risks, (d) provide personalized reports to employees, (e) provide aggregated reports to employers; and (f) trigger alert messages when the thresholds related to individual health conditions are exceeded (see Appendix B).

\subsection{Study design}

To measure users' perceptions of affordance, the researcher must develop a series of context-specific measurements by conducting qualitative research, reviewing existing literature, and/or cautiously adapting existing measures (Wang et al. 2015). Since the extant literature does not currently offer significant insight into our phenomenon of interest, we opted for an exploratory sequential mixed method study design, as illustrated in Figure 2 and described below. Similar to the 
study designs used in Wu (2012) and Lee et al. (2013), we initiated our investigation with a development phase that was driven by the need to obtain an in-depth understanding of the possible affordances of DOHS and if relational aspects played a role in shaping users' perceptions of this technology. To obtain divergent views on the phenomenon, we interacted with the designers of the Active@work artifact and conducted semi-structured interviews with future users of the system. The qualitative findings were used to derive hypotheses to be tested in the quantitative strand of this study. We will expand upon the procedure and findings from the development phase in the next section. After completion of the development phase, we moved to the corroboration phase, the aim of which was to assess the credibility of the inferences obtained from the previous steps. In so doing, we developed a questionnaire and conducted a web-based survey. Below, we will describe in detail our procedure and findings.

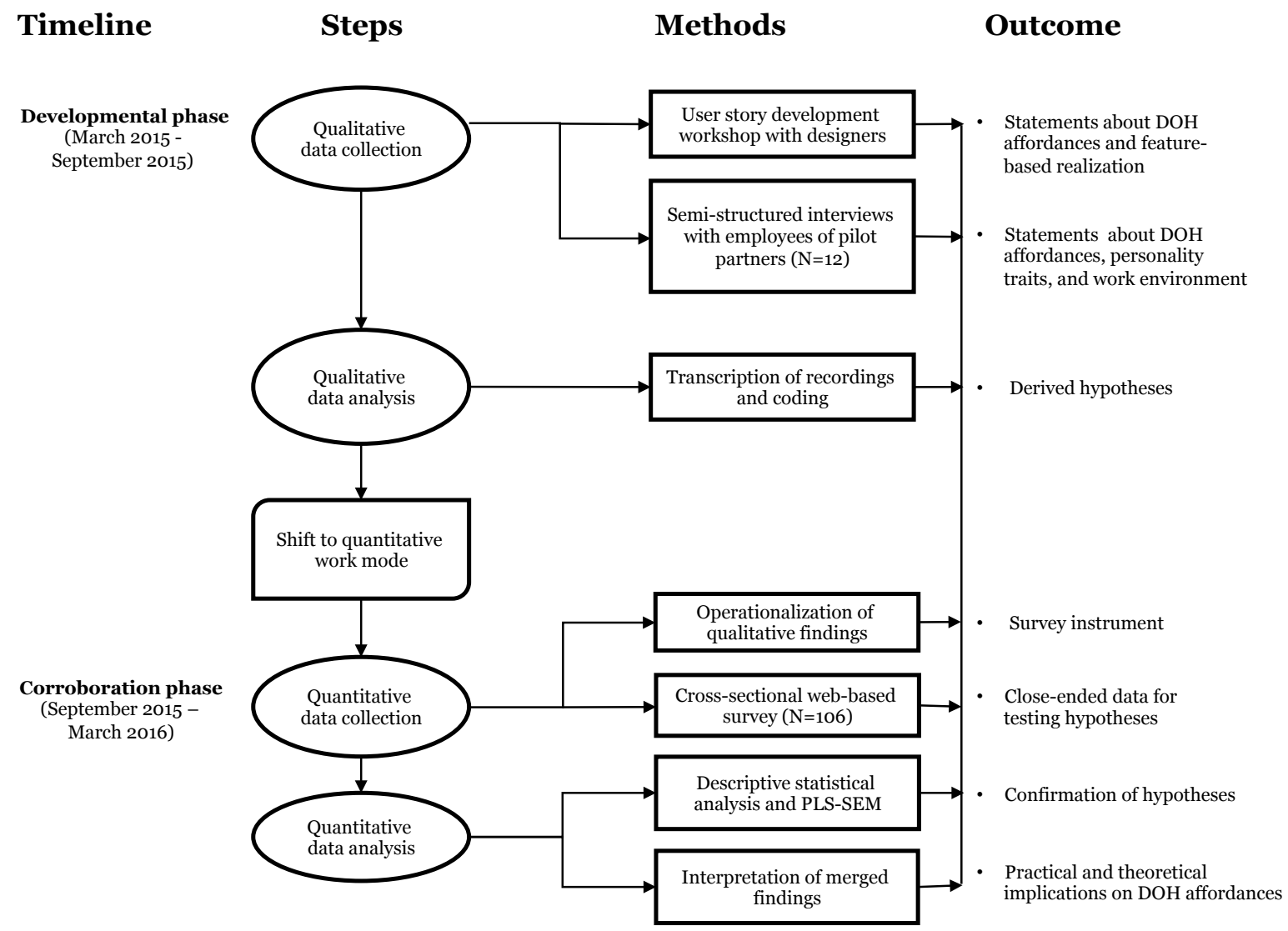

Fig 2. Overall research design

\section{Developmental phase}

As discussed above, the goal of the development phase was to improve our understanding of DOHS user adoption behavior by better understanding what are the main possible and expected DOHS functional aspects and which relational 
aspects may facilitate or limit the users interaction with DOHS. Since our aim was to inductively generate new insights, we began with a qualitative inquiry, which will be described below.

\subsection{Data collection and sample}

In March of 2015, we performed a user story development workshop with the design team of the Active@work project; our goal was to explore the functional and aesthetic properties of the future DOHS solution. The workshop, which was based on the user story methodology developed by Van der Veer and Van Welie (2003), lasted two full days and was organized by two researchers. One researcher played the role of moderator in order to facilitate the generation of a maximum number of different ideas and opinions in the time allotted; the other researcher was concerned with taking observational field notes and recording the process. The user stories developed from the workshop were documented and visualized with business process models; they led to the identification of four affordances: (1) visibility of personal health and wellbeing, (2) persuasiveness, (3) assistance (4) and controllability facilitated by an increased understanding of the affordances of the future DOHS.

Facilitated by an increased understanding of the affordances of the future DOHS, in the next step we conducted two rounds of semi-structured interviews at the site of the pilot partners. The objective of this phase was twofold. First, to grasp whether the employees perceive the derived designer affordances desirable. Second, we permitted an ongoing process of refocusing and reconceptualization, as suggested by Bouchard (1976), in order to allow the interviewees to reformulate their ideas more precisely by using examples from their daily work experience to identify the factors which embody their perception of the DOHS affordances.

To recruit respondents for the interviews, we considered the suggestion of Thompson (1966), who stated that opinions are best assessed by people: (1) with a special interest, (2) who can judge and provide dispassionate feedback, (3) with authority and expertise, (4) with general interest but no special expertise, or (5) who are uninformed and/or uninterested. Accordingly, we followed a purposive sampling strategy and actively involved employees likely to be affected by the introduction of DOHS by their employer. A total of 12 interviews with nine white-collar and three blue-collar workers were conducted between June and September of 2015. The respondents taking part in the qualitative inquiry (five male and seven female) were, on average, 48 years of age and had worked for approximately 12 years in their current positions. Three of the respondents were working in management positions and nine had no management responsibilities.

Each interview lasted approximately 60 minutes and began with broad, unobtrusive questions regarding the current occupational health program at the pilot partners and participants' previous personal experiences with quantified-self technologies (at work and/or home). This was followed by a clear definition of what we understand to be DOHS followed by presenting the derived designed affordances and more specific questions about the possible role of DOHS in the interviewees' areas of work and their expectations.

All interviews were recorded and the answers were transcribed verbatim; subsequently, these transcriptions were returned to the interviewees so that they could perform timely reviews for accuracy. In order to systematically analyze the interview transcripts, we used open coding (Strauss and Corbin 1998). Throughout the multiple rounds of reading and coding, we identified two important personal traits (stress vulnerability and attitude towards privacy) that drove employees' affordance 
perceptions, as well as two influencing factors emanating from the work environment (mental and physical pressure at work); all are detailed below.

\subsection{Findings from the user story development workshop}

As mentioned above, our discussions and interaction with the design team at the user story development workshop allowed us to derive four affordances DOHS might provide: (1) visibility of personal health and wellbeing, (2) persuasiveness, (3) assistance, and (4) controllability. Each of the identified affordances can be illustrated by different (functional and nonfunctional) features. In the following, we provide a brief definition of each affordance and exemplary features that manifest their perceptibility.

- Visibility of personal health and wellbeing refers to DOHS's ability to make users' occupational health behaviors visible. For employees, this visibility raises self-consciousness and prevents health-related risks; it might even be used to resolve and optimize personal issues such as sleep disorders (Swan 2012). It could also help organizations identify the behavioral patterns of its employees, which would support management in improving work performance and productivity. This affordance can be realized, for instance, with environmental sensors enabling access to data about users' surroundings (e.g., temperature, humidity, toxic gasses, air quality, light quality, noise), together with wearable sensors measuring the physiological parameters of the users when they are at work (e.g., mental fatigue, physical fatigue, bad eating habits, pain, insufficient movement, blood pressure, stress, etc.).

- Persuasiveness, in our case, refers to DOHS's ability to motivate and persuade employees to engage in healthy behavior. This could be realized through features supporting, for example, gamification, competition, and social interaction, such as a monthly challenge among co-workers or teams to collectively stop smoking or committing to performing a daily exercise routine (M. S. Patel et al. 2015).

- Assistance refers to DOHS's ability to inform users (and their co-workers) about potential health risks or emergency situations posed by their surroundings. To realize this affordance, the required functional feature could be a simple alert and messaging functionality or a more complex context-sensitive algorithmic decision-making functionality that informs users based on data from their environmental and physiological sensors (Schwaibold et al. 2002).

- Controllability refers to DOHS's ability to allow users control over their own data. The use of wearable devices generates a personal data trail that may or may not violate the privacy of the individual (Culnan and Williams 2009; Carpenter et al. 2016). Granular privacy settings that enable employees to limit access to their health-related data are therefore of the utmost importance to realizing this affordance, even though such settings might jeopardize organizational objectives such as ensuring a safer workplace (e.g., monitoring workers in potentially unhealthy environments such as refrigerated chambers (Corbellini et al. 2008)) or preventing workplace accidents at construction sites (Cheng et al. 2012).

The entire design team was convinced that if the system could properly transmit to users the described affordances, the initial intention of using DOHS would considerably increase. This led us to formulate our first hypothesis:

(H1) The perceptibility of DOHS's affordances will positively influence employees' use intentions. 


\subsection{Findings from the semi-structured interviews}

The interviews allowed us to investigate whether the designers' affordances are aligned with potential users' DOHS perceived affordances or not. In addition, we derived the main relational aspects of DOHS affordances that have an impact on employees' perceptions of functional aspects of DOHS affordances.

During the interviews, we identified that employees expected two core outcomes of DOHS adoption in their working environments: to manage and prevent work related stress and to enhance their physical condition at work. For instance, most of the interviewees considered stress as the main source of work related health issues: "We are not conscious of our health [and] in particular our stress. Maybe it [would be] interesting to have [a] different point of view, even it is from a machine. The other employee mentioned, "Stress is something important in our job and [a] precondition for our health. I had some people with [a] high level of stress for [a] long time and I saw how their health [was] impacted by that.

Depending on their job conditions and their experience to actively managing health issues at work, they perceived the effectiveness of the DOHS affordances differently. Regarding stress management, the interviewees with higher level of stress vulnerability perceived the DOHS affordances more effective than the other group with lower level of vulnerability. One employee with a high stress vulnerability responded: "For people like me, managing the stress is so important and knowing the process to manage it is not trivial right now. [DOHS] can be an assistant to improve these things. I am now 40 but when I am 55 I do not know if I can handle this level of stress.” In contrast, a respondent with superior coping abilities answered: "I don't see any contribution for me. I think with years of experience, I know how to deal with stress." Based on these reactions, we hypothesize:

(H2a) Stress vulnerability positively influences an employee's perception of DOHS affordances effectiveness.

Related to physical enhancement, employees with higher level of physical pressure could positively perceive the DOHS affordances. For instance, most of white collar employees we interviewed suffered from back pain because of long hours of sitting with wrong posture and expected that the system would help them to solve this issue. On the one hand, blue collar workers stated that the more the physical pressure increased, the more useful it would be to have a DOHS supporting their ability to minimize that pressure. In addition, it would help them to provide evidence of their hard work, which in turn could be used to protect them against further exigent tasks:

(H3a) Physical pressure at work positively influences an employee's perception of DOHS affordances effectiveness. When asking interviewees about their concerns regarding the DOHS affordances, we frequently received two particular reactions: privacy and the possibility of work interruption. In most interviews, when we asked about their concern, a frequent response was: "I see the benefit of the system, but how about my privacy?" The other interviewee mentioned: "[Personal] data is so sensitive. However, I suppose that it is supported in the design of such systems." Regardless of openness of employees to share their personal information with others at work, they were concern about their privacy: "Privacy? I have an open personality. I talk about my life to everyone in the organization. I go to my colleagues and talk about my life but because I want to do it. But in this case for me privacy is important because if I want to share my information I do it myself, but I don't like a system that shares my personal information with others." Nonetheless, some employees were willing to trade their privacy to access tangible or intangible value. For some, economic incentives would convince them to give up their privacy: "If 
there is an economic incentive then you say ok. I give up my privacy to get money or a bonus for it. It should be balanced, you know?" Based on the overall tendency expressed in the interviews, we hypothesize:

(H2b) Privacy concerns negatively influences an employee's perception of DOHS affordances effectiveness.

In addition to privacy, interviewees with higher mental pressure at work also mentioned negative effects of constant interacting with DOHS could interrupt their work, which would not only be disturbing, but would also require increased mental fitness for the employee to remain productive and efficient. Most of the interviewees were primarily concerned with the possibility of conflict between their work and non-work activities. For instance, one interviewee mentioned, "It is also about the interaction with the device; if it asks me every 15 minutes to interact then it is invasive, then I prefer to not use the system”. Correspondingly, we hypothesize:

(H3b) Mental pressure at work negatively influences an employee's perception of DOHS affordances effectiveness.

We graphically summarize the findings from the qualitative section of our study in Figure 3 . We further categorized the relational aspects into personality traits and work environment. Based on the findings of the qualitative phase, in the personality trait category, we hypothesized that stress vulnerability positively influences the employees' perception of affordances, whereas the employees' attitude toward privacy negatively influences their perception. In the work environment category, we hypothesized that the physical pressure positively influences the perception of affordances, while high mental pressure has a negative influence on perceiving the affordances of DOHS.

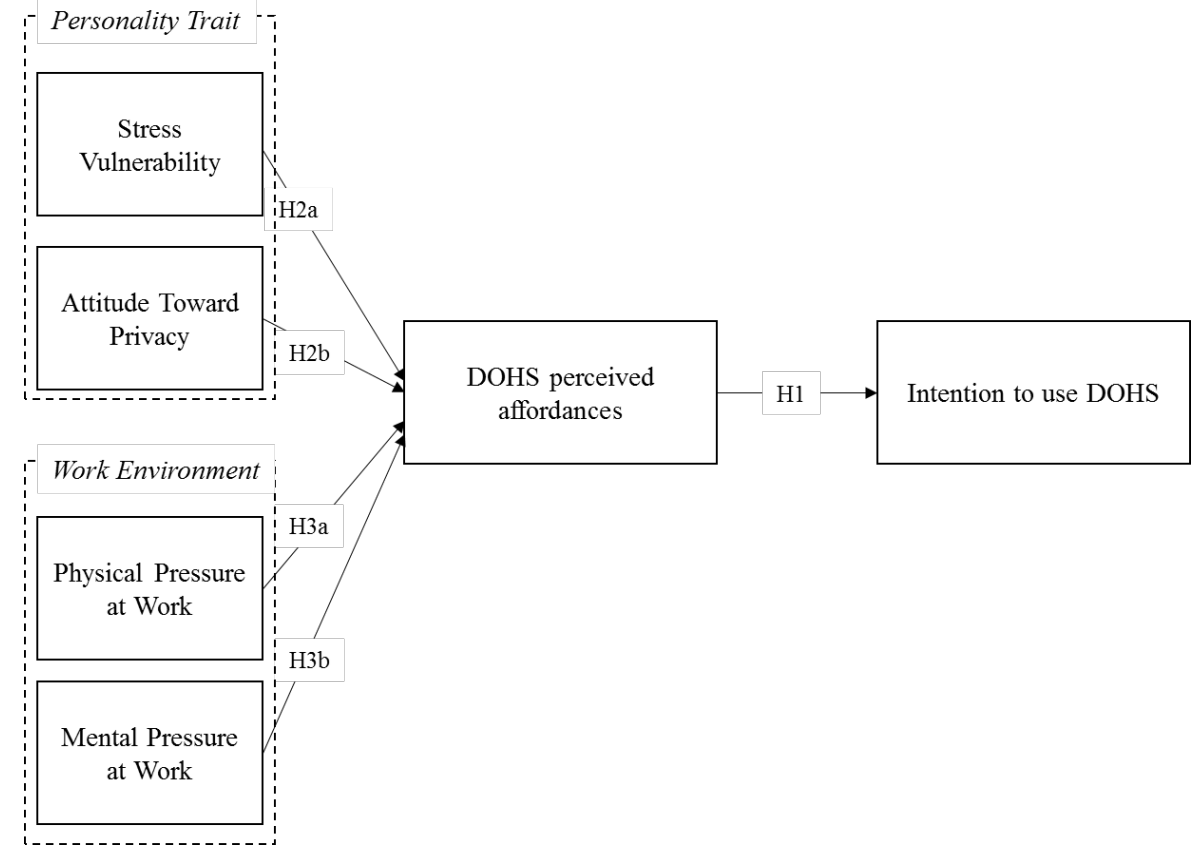

Fig. 3 Hypotheses derived from the user story development workshop and semi-structured interviews 


\section{Corroboration phase}

To test the derived hypotheses from the development phase, we initiated the quantitative strand of our study; from September to November of 2015, we operationalized and conducted a survey. Since our prior observations were far from being a well-developed a priori theory explaining the entire phenomenon of interest, we opted for a partial least squares (PLS) structural equation approach over the more common covariance-based approach. This reduced the risk of overfitting (Gefen and Straub 2005). In addition, compared to other statistical techniques, PLS does not depend upon multivariate normally-distributed data and it can be used with relatively small sample sizes (Chin 1998; Ringle et al. 2012). The tests were performed using SmartPLS version 2.0. Missing values were handled through mean replacement; bootstrapping was conducted with 500 resamples to assess path estimate significance (Bollen and Stine 1992). We expand upon the procedure and findings of the corroboration phase in the following sub-sections.

\subsection{Data collection and sample}

To obtain the necessary data for the quantitative part of our study, we designed a questionnaire consisting of four blocks of questions, including queries related to DOHS affordance perceptions, personality, working conditions, and future use intentions. To operationalize the constructs, we derived measurement items that either had been applied and validated in prior research or the wording for which was modified to fit the context of this study (Ajzen and Fishbein 1980). For the use intention construct, we used a single item measure because we had a singular object (DOHS) and one concrete attribute (intention) (Bergkvist and Rossiter 2007).

By means of a structured sorting exercise, as suggested by Moore and Benbasat (1991), with our 12 volunteers we were able to eliminate a number of items with low inter-item correlations within a single construct. The final list of measurement items can be found in the Appendix.

Respondents were recruited through the researchers' website (34.9\%) and by e-mail (65.1\%), resulting in a sample of 106 responses. Only responses were stored and subsequently analyzed, when respondents confirmed (by ticking a specific box in the online survey) that they were confronted with the introduction of some kind of occupational health program at work. The sample characteristics are summarized in Table 1. Out of the total sample, 37.74\% were female and 55.66\% male; $6.60 \%$ did not indicate a gender. The majority of respondents were highly educated with either a master's (62.26\%) or doctoral degree (22.64\%). Half of the respondents ranged between 35 and 55 years of age, and $10 \%$ were over 55 . Approximately $41.51 \%$ of the respondents had worked more than five years at their current employer, mainly in engineering $(30.19 \%)$ or IT-related $(43.40 \%)$ positions. Most participants were regular office workers (46.23\%) or lowlevel managers $(16.98 \%)$. 
Table 1 Sample Characteristics $(n=106)$

\begin{tabular}{|c|c|c|c|c|c|}
\hline Characteristic & $\mathbf{N}$ & $\%$ & Characteristic & $\mathbf{N}$ & $\%$ \\
\hline \multicolumn{3}{|l|}{ Gender } & \multicolumn{3}{|l|}{ Duration of employment in current organization } \\
\hline Female & 40 & $37.74 \%$ & Less than 5 years & 58 & $54.72 \%$ \\
\hline Male & 59 & $55.66 \%$ & $5-10$ years & 17 & $16.04 \%$ \\
\hline n. a. & 7 & $6.60 \%$ & More than 10 years & 27 & $25.47 \%$ \\
\hline \multicolumn{3}{|l|}{ Age } & n. a. & 4 & $3.77 \%$ \\
\hline Under 25 & 4 & $3.77 \%$ & \multicolumn{3}{|l|}{ Job function } \\
\hline 26 to 35 & 38 & $35.85 \%$ & IT & 46 & $43.40 \%$ \\
\hline 35 to 45 & 35 & $33.02 \%$ & Support services & 12 & $11.32 \%$ \\
\hline 46 to 55 & 16 & $15.09 \%$ & Marketing/Sales & 7 & $6.60 \%$ \\
\hline Over 55 & 12 & $11.32 \%$ & Engineering & 32 & $30.19 \%$ \\
\hline n. a. & 1 & $0.94 \%$ & Finance & 4 & $3.77 \%$ \\
\hline \multicolumn{3}{|l|}{ Perceived Health } & Administration & 8 & $7.55 \%$ \\
\hline Excellent & 12 & $11.32 \%$ & Human resources & 2 & $1.89 \%$ \\
\hline Very good & 49 & $46.23 \%$ & Other & 29 & $27.36 \%$ \\
\hline Good & 36 & $33.96 \%$ & \multirow{2}{*}{\multicolumn{3}{|c|}{ Job Level }} \\
\hline Fair & 7 & $6.60 \%$ & & & \\
\hline Poor & 0 & $0.00 \%$ & President or CEO & 2 & $1.89 \%$ \\
\hline n. a. & 2 & $1.89 \%$ & Level executive (CIO, CTO, COO, CMO, etc.) & 4 & $3.77 \%$ \\
\hline \multicolumn{3}{|l|}{ Education } & Vice President & 3 & $2.83 \%$ \\
\hline Elementary school & 0 & $0.00 \%$ & Director & 4 & $3.77 \%$ \\
\hline Middle/high school & 3 & $2.83 \%$ & Manager & 13 & $12.26 \%$ \\
\hline (2 year) College & 3 & $2.83 \%$ & Associate & 8 & $7.55 \%$ \\
\hline Master's degree & 66 & $62.26 \%$ & Team Leader & 18 & $16.98 \%$ \\
\hline Doctoral degree & 24 & $22.64 \%$ & Team Member & 49 & $46.23 \%$ \\
\hline Associate degree & 1 & $0.94 \%$ & Intern & 4 & $3.77 \%$ \\
\hline Professional degree & 6 & $5.66 \%$ & Other & 12 & $11.32 \%$ \\
\hline
\end{tabular}

\subsection{Findings from the structural equation modeling}

Applying PLS means specifying two distinct models (Ringle et al. 2012), a structural model describing the relationships or paths among the structural dimensions, and a measurement model linking the constructs with a set of operational measures. Following this two-step analytical procedure, the measurement model was examined and then the structural model was tested. 


\subsubsection{Measurement model}

To test the reliability and validity of the operationalized model, several criteria were used (see Table 2). The coefficient Cronbach's Alpha $(\alpha)$ was applied to determine the reliability of the operationalized constructs. Following Cortina (1993), the values for $\alpha$ should be greater than or equal to 0.8 for a good scale, 0.7 for an acceptable scale, and 0.6 for a scale used for exploratory purposes. All constructs complied with this quality measure. As $\alpha$ is biased against short scales of two or three items, which typically leads to an underestimation of reliability, composite reliability (CR) was used as an additional quality criterion. According to Chin (1998), values should be greater than 0.6 for exploratory purposes and greater than 0.7 for an adequate confirmatory model. All measured constructs complied with this criterion; however, the high values of the use intention (USI) construct were explained by the fact that we only used one binomial measuring item (see Appendix). To determine the convergent validity of the operationalized model, a further estimation of the average variance extracted (AVE) was performed. AVE captures the amount of explained variance relative to the total amount of variance and is considered sufficient if it has a value equal to or greater than 0.5 (Fornell and Larcker 1981). Not all items complied with this requirement, specifically the constructs for measuring mental pressure (MEP) and affordance perception (AFF).

Table 2 Reliability and inter-construct correlations

\begin{tabular}{|l|l|l|l|l|l|l|l|l|l|}
\hline Construct & USI & PC & SV & PHY & MEP & AFF & $a$ & AVE \\
\hline USI & 1.00 & & & & & & 1.00 & 1.00 & 1.00 \\
\hline PC & -0.20 & 1.00 & & & & & 0.90 & 0.92 & 0.70 \\
\hline SV & -0.03 & -0.01 & 1.00 & & & & 0.75 & 0.86 & 0.67 \\
\hline MEP & -0.09 & 0.02 & 0.19 & 1.00 & & & 0.72 & 0.80 & 0.45 \\
\hline PHY & -0.04 & -0.20 & 0.08 & 0.32 & 1.00 & & 0.68 & 0.81 & 0.60 \\
\hline AFF & 0.46 & -0.30 & 0.20 & -0.20 & 0.20 & 1.00 & 0.83 & 0.87 & 0.45 \\
\hline
\end{tabular}

This minor deviation may be caused by lower levels of internal consistency in the AFF and MEP. Following Chin (1998), the values should be greater than 0.6 for exploratory purposes and 0.7 for an adequate confirmatory model. From Table 3 we can see that items AFF8 and MEP5 are slightly below 0.6, but nonetheless the loading was highest with the right construct. 
Table 3 Item loadings and cross-loadings

\begin{tabular}{|c|c|c|c|c|c|c|c|c|}
\hline ITEM & $A F F$ & MEP & $P C$ & PHY & $S V$ & USI & $S D$ & Mean \\
\hline AFF1 & 0.79 & -0.13 & -0.31 & 0.18 & 0.18 & 0.38 & 0.49 & 0.60 \\
\hline AFF2 & 0.64 & -0.12 & -0.29 & 0.25 & 0.13 & 0.42 & 0.47 & 0.67 \\
\hline AFF3 & 0.71 & -0.12 & -0.25 & 0.15 & 0.17 & 0.19 & 0.49 & 0.58 \\
\hline AFF4 & 0.64 & -0.17 & 0.08 & -0.08 & 0.14 & 0.25 & 0.47 & 0.68 \\
\hline AFF5 & 0.69 & -0.24 & -0.13 & 0.05 & 0.06 & 0.43 & 0.46 & 0.70 \\
\hline AFFG & 0.68 & -0.10 & -0.14 & 0.02 & 0.17 & 0.20 & 0.47 & 0.66 \\
\hline AFF7 & 0.68 & -0.13 & -0.20 & 0.10 & 0.18 & 0.27 & 0.49 & 0.61 \\
\hline AFF8 & 0.58 & -0.09 & -0.17 & 0.24 & 0.03 & 0.21 & 0.49 & 0.62 \\
\hline MEP1 & -0.21 & 0.85 & 0.04 & 0.13 & 0.17 & -0.06 & 1.08 & 3.63 \\
\hline MEP2 & -0.10 & 0.69 & 0.01 & 0.37 & 0.13 & 0.08 & 1.12 & 2.79 \\
\hline MEP3 & -0.08 & 0.68 & 0.04 & 0.22 & 0.16 & -0.14 & 1.17 & 3.38 \\
\hline MEP4 & -0.14 & 0.60 & -0.02 & 0.29 & 0.08 & -0.15 & 1.10 & 3.41 \\
\hline MEP5 & -0.03 & 0.54 & -0.03 & 0.16 & 0.17 & 0.03 & 1.18 & 3.06 \\
\hline PC1 & -0.27 & 0.05 & 0.94 & -0.21 & -0.04 & -0.18 & 1.06 & 2.87 \\
\hline PC2 & -0.30 & 0.07 & 0.93 & -0.23 & 0.01 & -0.19 & 1.20 & 2.77 \\
\hline$P C 3$ & -0.15 & 0.03 & 0.82 & -0.14 & 0.05 & -0.16 & 1.21 & 2.76 \\
\hline PC4 & -0.08 & -0.03 & 0.64 & -0.02 & 0.13 & -0.26 & 1.20 & 2.12 \\
\hline PC5 & -0.30 & -0.05 & 0.83 & -0.15 & -0.06 & -0.15 & 1.08 & 2.99 \\
\hline PHY1 & 0.07 & 0.36 & -0.14 & 0.75 & 0.08 & 0.07 & 1.28 & 2.11 \\
\hline PHY2 & 0.20 & 0.28 & -0.18 & 0.87 & 0.10 & 0.07 & 1.12 & 1.72 \\
\hline PHY3 & 0.14 & 0.16 & -0.13 & 0.68 & 0.02 & -0.04 & 1.39 & 1.96 \\
\hline$S V 1$ & 0.18 & 0.12 & 0.02 & 0.08 & 0.83 & -0.02 & 1.06 & 2.17 \\
\hline$S V 2$ & 0.16 & 0.09 & -0.07 & 0.09 & 0.85 & -0.04 & 0.97 & 2.32 \\
\hline$S V^{3}$ & 0.14 & 0.29 & 0.04 & 0.02 & 0.77 & 0.00 & 1.03 & 2.79 \\
\hline USI & 0.46 & -0.09 & -0.20 & 0.04 & -0.03 & 1.00 & 0.46 & 0.71 \\
\hline
\end{tabular}

\subsubsection{Structural model}

To estimate the path coefficients, we performed a bootstrapping sampling with 500 resamples (Bollen and Stine 1992). Since PLS approaches do not attempt to minimize residual item covariance or make any distributional assumptions, the R-squared (R2) values and structural path t-values needed to be examined to determine the significance of the estimated paths. Table 4 gives an overview of the effect sizes we obtained by means of the SmartPLS path weighting scheme. The results are graphically summarized in Figure 4. 
Table 4 Standardized path coefficients $(\beta), t$-values and hypothesis evaluation

\begin{tabular}{|l|l|l|l|l|l|}
\hline & Path description & $\beta$ & t-value & $\varrho$-value & Result \\
\hline H1 & Affordance perception $\rightarrow$ use intention & 0.464 & 5.424 & 0.000 & Significant $* * *$ \\
\hline H2a & Stress vulnerability $\rightarrow$ affordance perception & 0.237 & 3.217 & 0.001 & Significant $* * *$ \\
\hline H2b & Privacy concerns $\rightarrow$ affordance perception & -0.242 & 2.222 & 0.027 & Significant $*$ \\
\hline H3a & Physical pressure $\rightarrow$ affordance perception & 0.228 & 1.987 & 0.047 & Significant $*$ \\
\hline H3b & Mental pressure $\rightarrow$ affordance perception & -0.316 & 2.182 & 0.030 & Significant $*$ \\
\hline
\end{tabular}

As shown in Table 4, our initial hypotheses were all supported by the structural model. The findings of the quantitative part of our study corroborated our initial assumption that perceived affordances have a particularly strong influence $(\beta=0.464)$ on DOHS use intention. While high levels of stress vulnerability $(\beta=0.237)$ and physical pressure $(\beta=0.228)$ have the tendency to positively shape the affordance perception of DOHS properties, high levels of mental pressure $(\beta=-$ $0.316)$ and serious privacy concerns $(\beta=-0.242)$ tend to have a negative influence. While this last influence is quite expected -since using wearable computing devices in DOHS scenarios entails the collection of an enormous amount of personal data and not everyone is likely to be open to that - an interesting finding is that people with superior abilities to cope with stress might draw more meaning and usefulness from such artifacts than people with fewer coping mechanisms or a higher affinity for becoming stressed. From the interviews, we learned that the idea of using a wearable computing device for DOHS purposes provokes stress in some employees. Whereas stress-resistant employees might not experience this sensation or may be better prepared to cope, the additional stress provoked in the other group could outweigh the potential positive effects of implementing a DOHS. A similar interpretation could apply to the work environment. Whereas DOHS may afford a better means of measuring and controlling physical pressure at work, environments with high loads of mental pressure may perceive DOHS as a distraction or a new source of stress, which could explain the identified negative influence. 


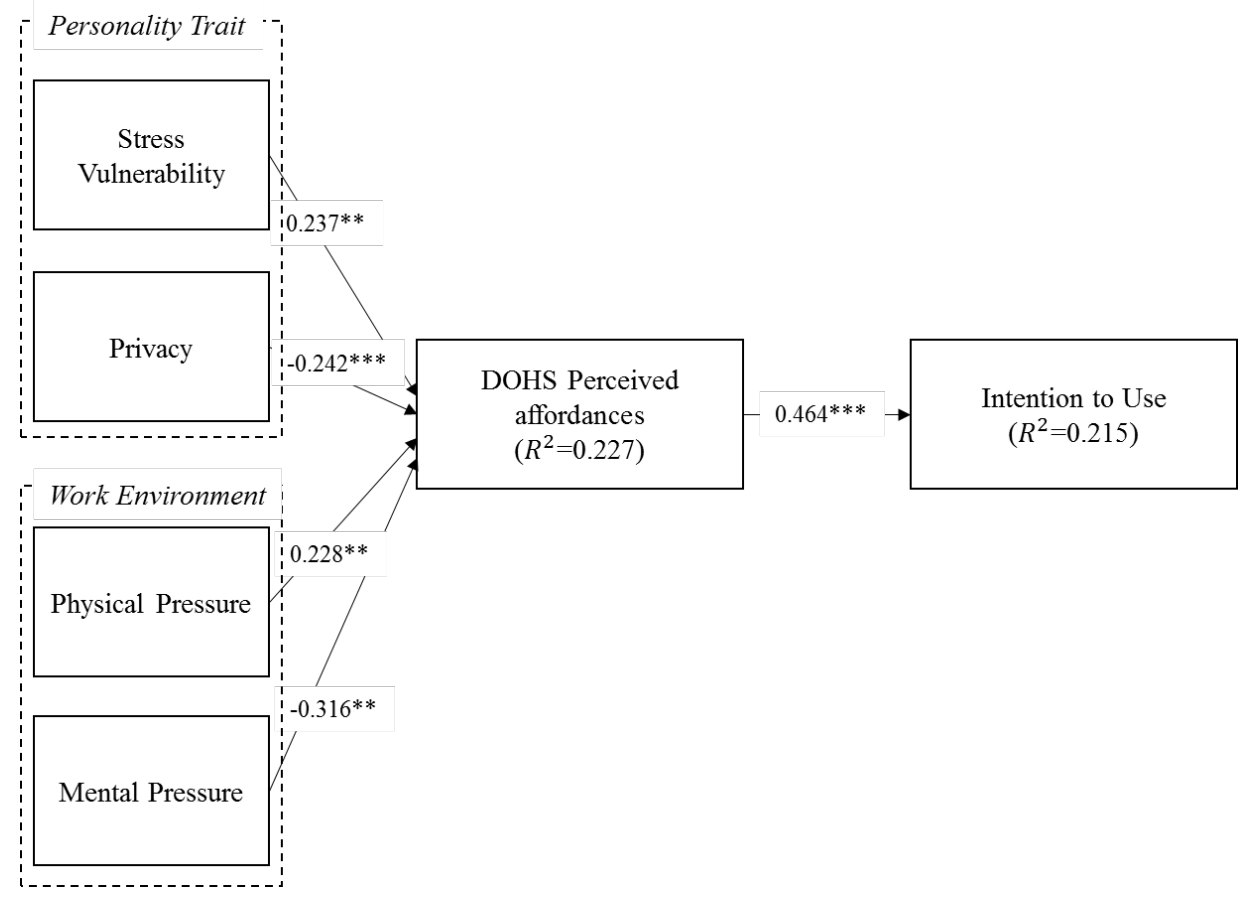

Fig. 4 Results of the structural model estimation with significance: ${ }^{*} \mathrm{p}<0.05 ;{ }^{* *} \mathrm{p}<0.01$; ${ }^{* *} \mathrm{p}<0.001$. 


\section{Discussion and conclusion}

This study argues that introducing digitized health-promoting systems such as DOHS have potential benefits for both organizations and individuals. Although the relative advantages of DOHS for organizations are clear (direct impact on the lower levels of health-related costs and absenteeism, and indirect impact on employees' performance and productivity) it is dependent to the voluntary adoption by employees. However, the relative advantages for employees are uncertain (possibly work-related health benefits and more security). Since for legal reasons the organizational advantages depend upon voluntary adoption by employees, it is important to reduce adoption barriers. The successful voluntary use of IT innovations in organizational settings is likely to occur through a continuous interplay between users mental models, actions and organizational elements (Elbanna and Linderoth 2015). Therefore, system designers and managers need to influence users' mental models and provide favorable use cases to make it possible for users to adopt the new technology. With this goal in mind, the present study was designed to determine factors impacting users' intention to use DOHS. Using the affordance approach, we determined that it was possible to measure user intention via the affordance concept. Two studies were conducted to explore these factors: a comprehensive qualitative study (development phase) with the goal of obtaining an in-depth understanding of the possible affordances and contextual factors impacting their perceptibility, and a quantitative study (corroboration phase) in order to test the assumptions from the earlier phase.

The results of the development phase indicate that from the designers' and potential users' points of view, there are four key affordances for DOHS designs: (1) visibility of personal health and wellbeing as DOHS's ability to make users' occupational health behaviors visible, (2) persuasiveness as DOH's ability to motivate and persuade employees to engage in healthy behavior, (3) assistance as DOHS's ability to inform users and their co-workers of potential health risks or emergency situations in their surroundings, and (4) controllability as DOHS's ability to give users control over their data. The development phase of the study also indicated that the stress vulnerability and attitude of employees towards privacy are the main personal traits that have an impact on the perceptibility of DOHS affordances. Work-related physical and mental pressures were also hypothesized as factors impacting the perceptibility of DOHS affordances. Our analysis affirmed the positive impact of stress vulnerability and negative impact of privacy concerns on perceptibility affordances. In addition, mental pressure at work showed a negative impact, while physical pressure showed a positive impact on the employees' perception of DOHS affordances.

\subsection{Implications for practice and theory}

Analyzing the factors impacting employees' perceptions of DOHS affordances reveals DOHS's tensional nature. While the DOHS is expected to support employees in their efforts to manage work-related stress, task interruptions, which are caused by interactions with the technology (alerts, recommendations, reminders, etc.), can also provoke stress in work environments with high levels of mental pressure. The studies illustrating the negative impact of work interruption on a person's psycho-physiological state are in line with the findings of this study (Mark et al. 2008; Zijlstra et al. 1999). Therefore, system designers should pay more attention to systems-related interruption issues. It is important to consider that the negative impact of interruption is context dependent. The results of this study show that employees in work environments with high levels of mental pressure are more concerned with the degree of disturbance generated by the system. Since interruption management has been thoroughly studied in the HCI field, the existing guidance for explicitly 
designing successful interruption management solutions in that field can be used as the foundation for similar solutions in DOHS designs (McFarlane and Latorella 2002).

Privacy is another employee concern (and the main barrier), which underscores the negative impact of employees' perceptions of DOHS's affordances; this must be cautiously addressed during the specifications of DOHS's technical and organizational requirements. On the technical side, designers should base their technical considerations on privacy-aware monitoring architecture (Hu et al. 2010). However, applying this framework to systems design could reduce data accuracy. Precision systems, such as those dealing with health data for DOHS, play an important role; health-related decisions depend heavily on accurate and timely data. Thus, there is a need for balance between accuracy and privacy in technical systems design. On the organizational side, decision makers must understand their organization's culture and general attitude towards DOHS. In so doing, they may be able to design different interventions - such as incentives for participation - which could reduce resistance and motivate employees to use such systems, even though they would have to sacrifice privacy. As Majchrzak and Markus (2012) have argued, affordance theory has significant implications for the interpretation of human and organizational technology-related use behavior when it is applied to a specific context. Thus, researchers should use qualitative research to develop their own measurements of technology affordance for their particular categories of technology and use settings (Wang et al. 2015). Using the exploratory sequential mixed method will allow researchers to empirically test their context-specific conceptual models of affordances that they develop in the qualitative phase of their research. Although affordance theory may help to avoid some of the limitations of former adoption theories (which were discussed in theoretical foundation section), we may face certain limitations with regards to applicability. For instance, even though the theory of affordance has received a renewed level of attention in IS literature, there is no clear and common understanding of the concept of affordance throughout the discipline. Most affordance studies in IS are non-conceptual, broad, and perhaps even vague (Pozzi et al., 2014).

\subsection{Limitations and future work}

Like all research, this study has several limitations. The major restriction pertains to the sample and project setting (Active@work). Focusing only on two work environments-one with a high level of mental workload and the other with a high level of physical workload-limited our target sample to white and blue collar workers while we developed our conceptual model. Therefore, the derived factors might not represent an exhaustive list of relational aspects. Thus, future research should examine the attitudes of different populations in other work environments. Also, since this study was limited to the pre-implementation phase, it was not possible to study actual behavior. It would be interesting to go beyond the perceptions and intentions, and assess user choices made during the appropriation of identified DOHS affordances. Another way to extend this research is to conduct a comparative study of employees' attitudes towards DOHS as they vary among different organizational roles. The qualitative phase of this research revealed that management-level employees had completely different views towards the different DOHS affordances than did employees without any management responsibilities. For instance, while managers tended to be positive about the persuasiveness affordance, believing that gamification and competition might motivate employees to change their behaviors, employees without management responsibilities were more interested in improving their own levels of self-consciousness through the visibility affordance. They were not at all interested in competing with their colleagues. In this sense, more contextually nuanced studies would 
reveal more details of particular help in, which could be of particular help in technically and organizationally designing and adapting DOHS.

\section{References}

Ajzen, I., \& Fishbein, M. (1977). Attitude-behavior relations: A theoretical analysis and review of empirical research. Psychological Bulletin, 84(5), 888-918.

Ajzen, I., \& Fishbein, M. (1980). Understanding attitudes and predicting social behavior. Englewood Cliffs, NJ: Prentice-Hall.

Al-Natour, S., \& Benbasat, I. (2009). The adoption and use of IT artifacts: A new interaction-centric model for the study of user-artifact relationships. Journal of the Association for Information Systems, 10(9), 661-685.

Atallah, L., Lo, B., Ali, R., King, R., \& Yang, G.-Z. (2009). Real-time activity classification using ambient and wearable sensors. IEEE Transactions on Information Technology in Biomedicine, 13(6), 1031-1039.

Balci, B., Rosenkranz, C., \& Schuhen, S. Identification of different affordances of information technology systems (2014): In Proceedings of the European Conference on Information Systems, Tel Aviv, Israel.

Bergkvist, L., \& Rossiter, J. R. (2007). The predictive validity of multiple-item versus single-item measures of the same constructs. Journal of Marketing Research, 44(2), 175-184.

Bollen, K. A., \& Stine, R. A. (1992). Bootstrapping goodness-of-fit measures in structural equation models. Sociological Methods \& Research, 21(2), 205-229.

Bouchard, T. J. (1976). Field research methods: Interviewing, questionnaires, participant observation, unobtrusive measures. In M. D. Dunnette (Ed.), Handbook of industrial and organizational psychology (pp. 363-414). Chicago, IL: RandMcNally College Publishing Company.

Carpenter, D., McLeod, A., Hicks, C., \& Maasberg, M. (2016). Privacy and biometrics: An empirical examination of employee concerns. Information Systems Frontiers, (forthcoming), 1-20, doi:10.1007/s10796-016-9667-5.

Cheng, T., Migliaccio, G. C., Teizer, J., \& Gatti, U. C. (2012). Data fusion of real-time location sensing and physiological status monitoring for ergonomics analysis of construction workers. Journal of Computing in Civil Engineering, 27(3), 320335.

Chin, W. W. (1998). The partial least squares approach to structural equation modeling. In G. A. Marcoulides (Ed.), Modern methods for business research (pp. 295-336). Mahwah, NJ: Lawrence Erlbaum Associates.

Corbellini, S., Ferraris, F., \& Parvis, M. (2008). A system for monitoring workers' safety in an unhealthy environment by means of wearable sensors. In Proceedings of the Instrumentation and Measurement Technology Conference, Victoria, Canada.

Cortina, J. M. (1993). What is coefficient alpha? Examination of theory and applications. Journal of Applied Psychology, 78(1), 98-104.

Culnan, M. J., \& Williams, C. C. (2009). How ethics can enhance organizational privacy: Lessons from the choicepoint and TJX data breaches. MIS Quarterly, 33(4), 673-687.

Davis, F. D. (1986). A technology acceptance model for empirically testing new end-user information systems: Theory and results. Dissertation, Massachusetts Institute of Technology Sloan School of Management, Cambridge, MA.

Elbanna, A., \& Linderoth, H. C. (2015). The formation of technology mental models: The case of voluntary use of technology in organizational setting. Information Systems Frontiers, 17(1), 95-108. 
Engels, J. A., van der Gulden, J. W., Senden, T. F., \& van't Hof, B. (1996). Work related risk factors for musculoskeletal complaints in the nursing profession: results of a questionnaire survey. Occupational and environmental medicine, 53(9), 636-641.

Faraj S, and Azad B. (2012). The materiality of technology: An affordance perspective, in: Leonardi PM, Nardi BA, Kallinikos J. (eds.) Materiality and organizing: Social interaction in a technological world, Oxford University Press, Oxford, UK, pp. 237-258.

Fayarda, A.-L., \& Weeks, J. (2014). Affordances for practice. Information and Organization, 24(4), 236-249.

Fingas, R. (2015). IBM adopts Apple watch for internal fitness initiative \& Watson-linked health app. http://appleinsider.com/articles/15/10/27/ibm-adopts-apple-watch-for-internal-fitness-initiative-watson-linkedhealth-app2016. Accessed September 7, 2016.

Fornell, C., \& Larcker, D. F. (1981). Evaluating structural equation models with unobservable variables and measurement error. Journal of Marketing Research, 18(1), 39-50.

Gefen, D., \& Straub, D. (2005). A practical guide to factorial validity using PLS-graph - tutorial and annotated example. Communications of the Association for Information Systems, 16(5), 91-109.

Gibson, \& James J (Eds.). (1979). The theory of affordances, the ecological approach to visual perception. Boston: Houghton Mifflin Harcourt.

Greenhalgh, T., Robert, G., MacFarlane, F., Bate, P., \& Kyriakidou, O. (2004). Diffusion of innovations in service organizations: Systematic review and recommendations. The Milbank Quarterly, 82(4), 581-629.

Grgecic, D., Holten, R., \& Rosenkranz, C. (2015). The impact of functional affordances and symbolic expressions on the formation of beliefs. Journal of the Association for Information Systems, 16(7), 580-607.

$\mathrm{Hu} \mathrm{H}, \mathrm{Xu}$ J, and Lee DL, (2010). PAM: An efficient and privacy-aware monitoring framework for continuously moving objects, IEEE Transactions on Knowledge and Data Engineering, 22(3), 404-419.

Hutchby, I. (2001). Technologies, texts and affordances. Sociology, 35(2), 441-456.

Lee, S.-H., Nohb, S.-E., \& Kim, H.-W. (2013). A mixed methods approach to electronic word-of-mouth in the openmarket context. International Journal of Information Management, 33(4), 687-696.

Lekaa, S., Jaina, A., Zwetslootb, G., \& Coxa, T. (2010). Policy-level interventions and work-related psychosocial risk management in the european union. Work \& Stress: An International Journal of Work, Health \& Organisations, 24(3), 298307.

Leonardi, P. M. (2011). When flexible routines meet flexible technologies: Affordance, constraint, and the imbrication of human and material agencies. MIS Quarterly, 35(1), 147-168.

Leonardi, P. M. (2013). When does technology use enable network change in organizations? A comparative study of feature use and shared affordances. MIS Quarterly, 37(3), 749-775.

Leonardi, P. M., \& Barley, S. R. (2010). What's under construction here? Social action, materiality, and power in constructivist studies of technology and organizing. The Academy of Management Annals, 4(1), 1-51.

Maier, J. R. A., M. Fadel, G., \& Battisto, D. G. (2009). An affordance-based approach to architectural theory, design, and practice. Design Studies, 30(4), 393-414.

Majchrzak, A., \& Markus, M. L. (2012). Technology affordances and constraints in management information systems (MIS). In E. Kessler (Ed.), Encyclopedia of Management Theory. Thousand Oaks: Sage Publications. 
Markus, M. L., \& Silver, M. S. (2008). A foundation for the study of IT effects: A new look at Desanctis and Poole's concepts of structural features and spirit. Journal of the Association for Information Systems, 9(10), 609-632.

McFarlane DC, and Latorella KA, (2002). The scope and importance of human interruption in human-computer interaction design, Human-Computer Interaction, 17(1), 1-61.

Moore, G., \& Benbasat, I. (1991). Development of an instrument to measure the perceptions of adopting an information technology innovation. Information Systems Research, 2(3), 192-222.

Nieuwenhuijsen, K., Bruinvels, D., Frings-Dresen, \& M (2010). Psychosocial work environment and stress-related disorders, a systematic review. Occupational Medicine, 60(4), 277-286.

Norman, D. A (1988). The psychology of everyday things. Basic Books, New York, NY.

Norman, D. A. (1999). Affordance, conventions, and design. ACM Interactions, 6(3), 38-43.

Olson, P. (2014). Wearable tech is plugging into health insurance. http://www.forbes.com/sites/parmyolson/2014/06/19/wearable-tech-health-insurance/2016. Accessed September 7, 2016.

Oreg, S. (2003). Resistance to change: developing an individual differences measure. Journal of Applied Psychology, 88(4), 680693.

Patel, M. S., Asch, D. A., \& Volpp, K. G. (2015). Wearable devices as facilitators, not drivers, of health behavior change. Journal of the American Medical Association, 313(5), 459-460.

Patel, S., Park, H., Bonato, P., Chan, L., \& Rodgers, M. (2012). A review of wearable sensors and systems with application in rehabilitation. Journal of Neuroengineering and Rehabilitation, $9(1), 1$.

Piccoli, G., \& Pigni, F. (2013). Harvesting external data: The potential of digital data streams. MIS Quarterly Executive, 12(1), 53-64.

Pozzi, G., Pigni, F., \& Vitari, C. (2014) Affordance theory in the IS discipline: A review and synthesis of the literature. In Proceedings of the 20th Americas Conference on Information Systems, Savannah, USA.

Ringle, C. M., Sarstedt, M., \& Straub, D. W. (2012). A critical look at the use of PLS-SEM in MIS Quarterly. MIS Quarterly, 36(1), iii-xiv.

Schwaibold, M., Gmelin, M., von Wagner, G., Schochlin, J., \& Bolz, A. (2002). Key factors for personal health monitoring and diagnosis devices. In Proceedings of the 2nd Conference on Mobile Computing in Medicine, Heidelberg, Germany.

Smith, H. J., Milberg, S. J., \& Burke, S. J. (1996). Information privacy: measuring individuals' concerns about organizational practices. MIS Quarterly, 20(2), 167-196.

Strauss, A. L., \& Corbin, J. (1998). Basics of qualitative research: Techniques and procedures for developing grounded theory (2ed.). Newbury Park: Sage.

Sun, J., \& Qu, Z. (2015). Understanding health information technology adoption: A synthesis of literature from an activity perspective. Information Systems Frontiers, 17(5), 1177-1190.

Swan, M. (2012). Health 2050: The realization of personalized medicine through crowdsourcing, the quantified self, and the participatory biocitizen. Journal of Personalized Medicine, 2(3), 93-118.

Thompson, G. (1966). The evaluation of public opinion, in: Berelson, B., Janowitz, M. (Eds.), Reader in Public Opinion and Communication (pp. 7-12). New York: Free Press.

Van der Heijden H. (2004). User acceptance of hedonic information systems. MIS Quarterly, 28(4), pp. 695-704. 
van der Veer, G. C., \& van Welie, M. (2003). Dutch-designing for users and tasks from concepts to handles. In D. Diaper, \& A. S. Neville (Eds.), The handbook of task analysis for human-computer interaction (pp. 155-173): Lawrence Erlbaum Associates.

Vitari, C., \& Pigni, F. (2014). DDGS affordances for value creation. In L. Caporarello, B. Di Martino, \& M. Martinez (Eds.), Smart organizations and smart artifacts (pp. 9-16). New York: Springer.

Vyas, D., Fitz-Walter, Z., Mealy, E., Soro, A., Zhang, J., \& Brereton, M. (2015). Exploring physical activities in an employer-sponsored health program. In Proceedings of the $33 \mathrm{rd}$ Annual ACM Conference Extended Abstracts on Human Factors in Computing Systems, Seoul, Republic of Korea.

Wang, N., Carte, T., \& Schwarzkopf, A. (2015). How should technology affordances be measured? An initial comparison of two approaches. In Proceedings of the 21st Americas Conference on Information Systems, Puerto Rico.

Wilson, J. R., \& Sharples, S. (2015). Evaluation of human work (4ed.). London: CRC Press.

World Health Organization (1995). Global strategy on occupational health for all: The way to health at work, recommendation of the second meeting of the who collaborating centres in occupational health, http://www.who.int/occupational_health/globstrategy/en/. Accessed September 7, 2016.

Wu, D. J., Ding, M., \& Hitt, L. M. (2013). IT implementation contract design: Analytical and experimental investigation of IT value, learning, and contract structure. Information Systems Research, 24(3), 787-801.

Wu, P. F. (2012). A mixed methods approach to technology acceptance research. Journal of the Association for Information Systems, 13(3), 172-187.

Zijlstra FR, Roe RA, Leonora AB, and Krediet I, (1999). Temporal factors in mental work: Effects of interrupted activities, Journal of Occupational and Organizational Psychology, 72(2), 163-185. 
Appendix A - Measurement items

\begin{tabular}{|c|c|c|c|}
\hline Construct & Scale & Item & Description \\
\hline \multirow[t]{8}{*}{$\begin{array}{l}\text { Affordance } \\
\text { perception (AFF); } \\
\text { self-developed }\end{array}$} & \multirow{16}{*}{ 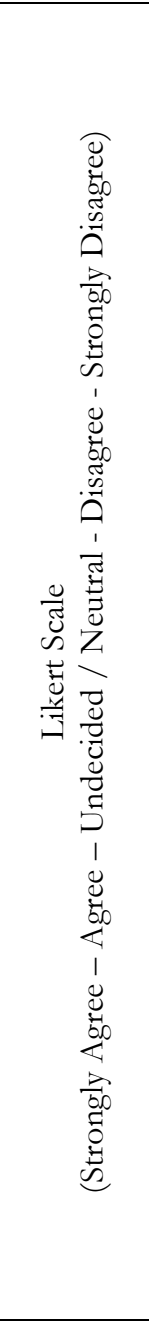 } & AFF1 & $\begin{array}{l}\text { I find having access to my health data at work (e.g. mental fatigue, } \\
\text { physical fatigue, bad eating habit, pains, not enough movement, blood } \\
\text { pressure, stress) is effective }\end{array}$ \\
\hline & & AFF2 & $\begin{array}{l}\text { I find having access to data about environment status (e.g. temperature, } \\
\text { humidity, toxic gasses, air quality, light quality, noise, missing equipment, } \\
\text { and ergonomics) is effective }\end{array}$ \\
\hline & & AFF3 & $\begin{array}{l}\text { With my colleagues (group) to share and compete to change a behavior } \\
\text { or cheer each other is effective }\end{array}$ \\
\hline & & AFF4 & $\begin{array}{l}\text { I find having control over my data with granular privacy settings that } \\
\text { enable me to limit access to my information is effective }\end{array}$ \\
\hline & & AFF5 & $\begin{array}{l}\text { Having the option to periodically analysis my health status on a } \\
\text { graphical dashboard is effective }\end{array}$ \\
\hline & & AFF6 & I find getting alerts with healthy recommendation at work is effective \\
\hline & & AFF7 & $\begin{array}{l}\text { I find alerting someone else in my organization when my health is at } \\
\text { stake (e.g. work related injury, fall detection) is effective }\end{array}$ \\
\hline & & AFF8 & $\begin{array}{l}\text { I find having someone in charge of monitoring, analyzing and } \\
\text { improving the wellbeing of employees based on the health and } \\
\text { environmental information of employees is effective }\end{array}$ \\
\hline \multirow{5}{*}{$\begin{array}{l}\text { Privacy concerns } \\
\text { (PC) adapted from } \\
\text { (Smith et al. 1996) }\end{array}$} & & PC1 & $\begin{array}{l}\text { I am concerned that the information I disclosed to the system may be } \\
\text { misused }\end{array}$ \\
\hline & & PC2 & $\begin{array}{l}\text { I am concerned that my personal health status information gathered by } \\
\text { the sensors may be misused. }\end{array}$ \\
\hline & & PC3 & $\begin{array}{l}\text { I am concerned that my personal health information can be used against } \\
\text { my status in the organization. }\end{array}$ \\
\hline & & PC4 & $\begin{array}{l}\text { I am concerned that environmental information can be used against my } \\
\text { status in the organization. }\end{array}$ \\
\hline & & PC5 & $\begin{array}{l}\text { I am concerned that my information on this platform may be used in a } \\
\text { way I did not foresee. }\end{array}$ \\
\hline \multirow[t]{3}{*}{$\begin{array}{l}\text { Stress vulnerability } \\
\text { (SV) adapted from } \\
\text { (Oreg 2003) }\end{array}$} & & SV1 & $\begin{array}{l}\text { If I were to be informed that there is going to be a significant change } \\
\text { regarding the way things are done in my work, I would probably feel } \\
\text { stressed. }\end{array}$ \\
\hline & & SV2 & When I am informed of a change of plans, I tense up a bit. \\
\hline & & SV3 & When things don't go according to plans, it stresses me out \\
\hline \multirow{5}{*}{$\begin{array}{l}\text { Mental pressure } \\
\text { (MEP) adapted } \\
\text { from (Engels et al. } \\
\text { 1996) }\end{array}$} & \multirow{8}{*}{ 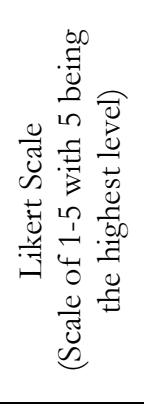 } & MEP1 & $\begin{array}{l}\text { On a scale of } 1-5 \text { with } 5 \text { being the highest pressure level, how do you } \\
\text { rate your work pressure? [Working under time pressure] }\end{array}$ \\
\hline & & MEP2 & [Inability to interrupt work] \\
\hline & & MEP3 & [Increased work pressure] \\
\hline & & MEP4 & [Work disturbed by unforeseen events] \\
\hline & & MEP5 & [Constant change of duty/tasks] \\
\hline \multirow{3}{*}{$\begin{array}{l}\text { Physical pressure } \\
\text { (PHY) adapted } \\
\text { from (Engels et al. } \\
1996)\end{array}$} & & PHY1 & $\begin{array}{l}\text { On a scale of } 1-5 \text { with } 5 \text { being the highest physical stress level, how do } \\
\text { you rate your physical stress at work? [Standing] }\end{array}$ \\
\hline & & PHY2 & [Walking] \\
\hline & & PHY3 & [Lifting heavy burdens] \\
\hline $\begin{array}{l}\text { Use intention } \\
\text { (USI) }\end{array}$ & 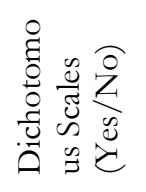 & USI & $\begin{array}{l}\text { Assuming you have access to the Active@work, would you use it during } \\
\text { the forthcoming } 12 \text { months? }\end{array}$ \\
\hline
\end{tabular}


Appendix B - Screenshots of cognitive module of Active@work platform

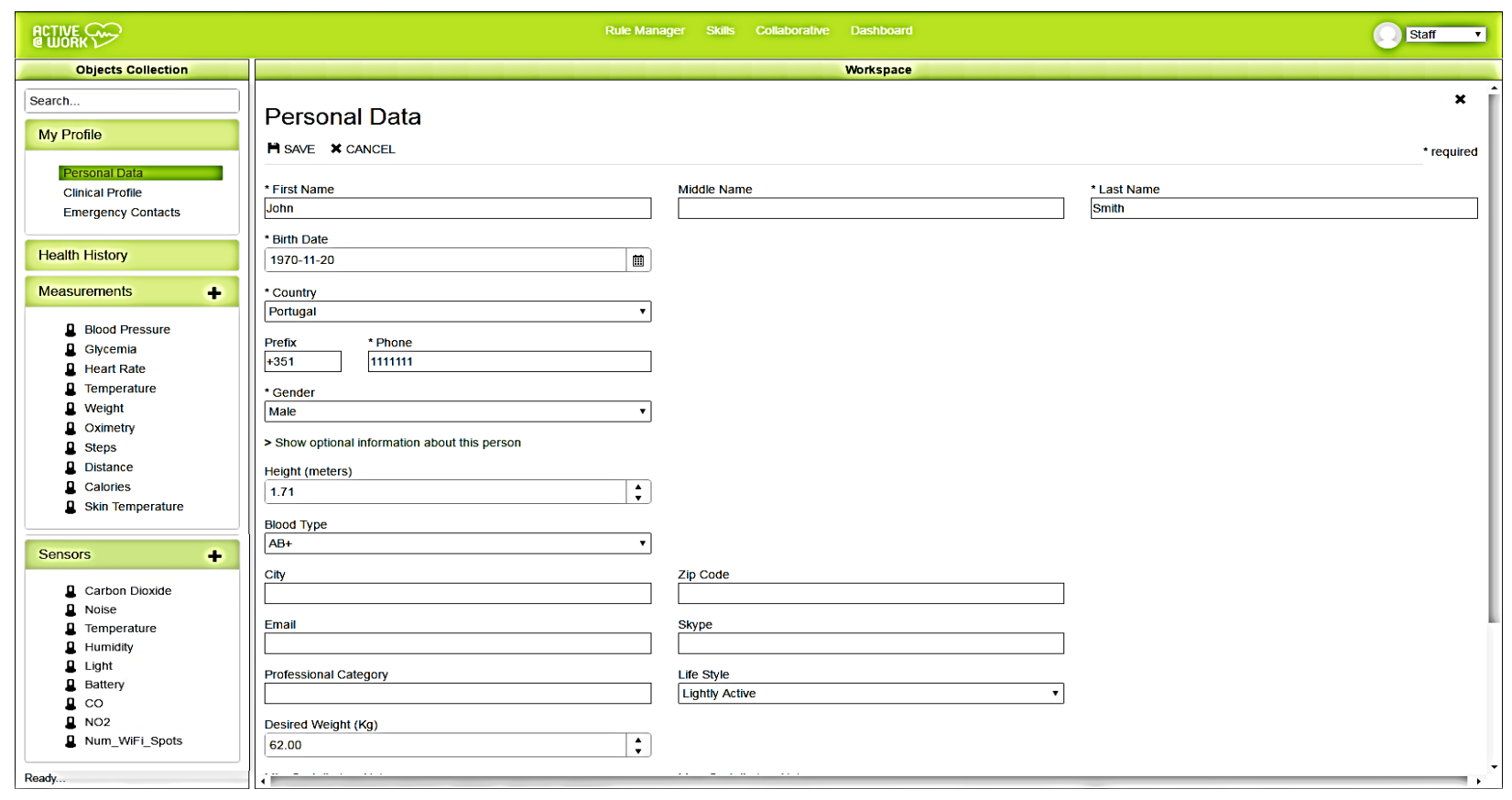

Fig. B1 Active@work workspace

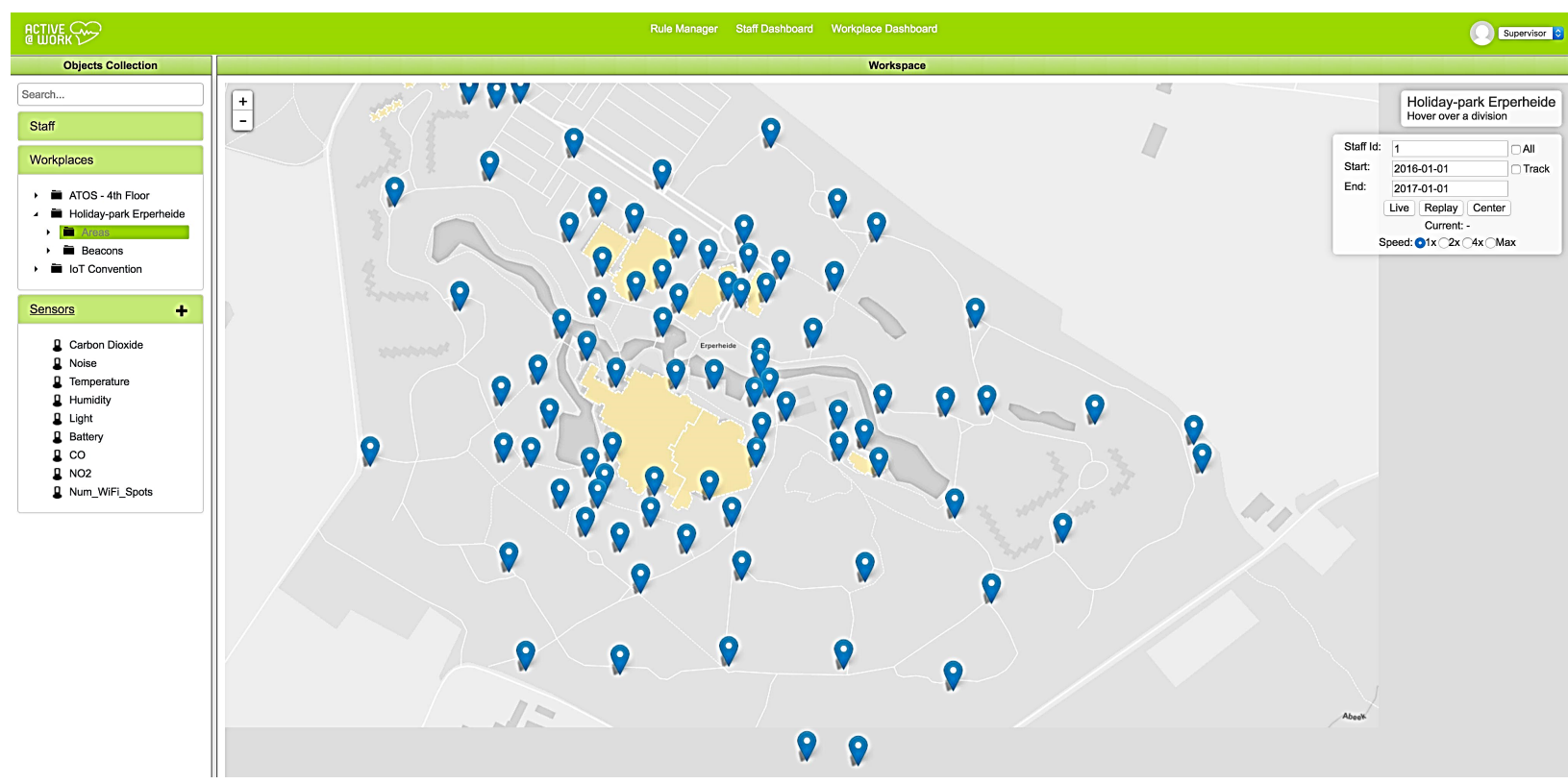

Fig. B2 Monitoring the condition of workplace environment and the location of employees with Active@work 

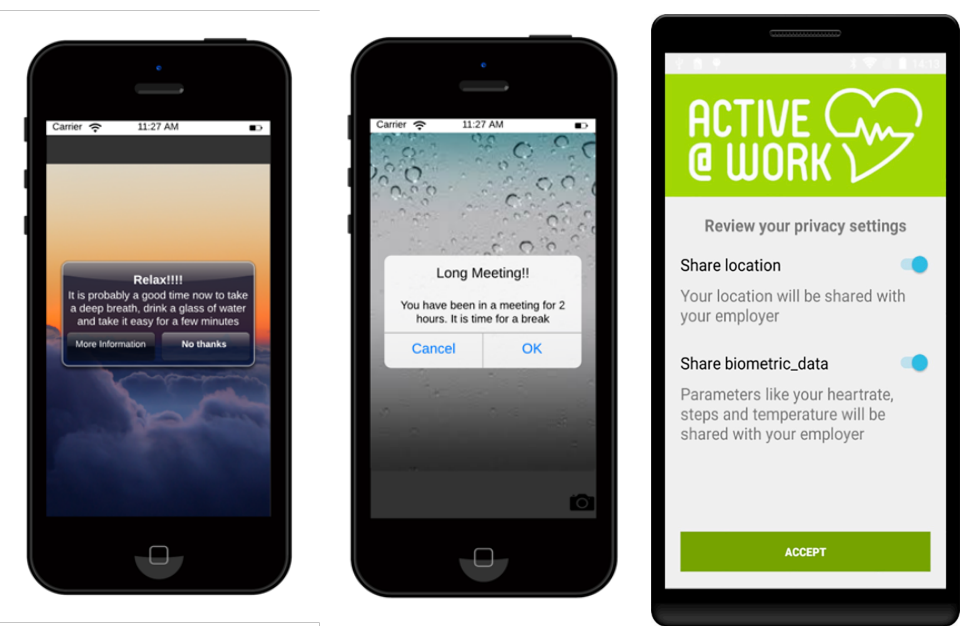

Fig. B3 Exemplary Active@work triggered alerts messages and privacy settings 